\title{
PERANCANGAN SISTEM INFORMASI INSTRUMEN KURIKULUM DAN EVALUASI RPS STUDI KASUS: PROGRAM STUDI SISTEM INFORMASI
}

\author{
Yohannes Accrus Alldy Indrawan ${ }^{1)}$ \\ 1) Sistem Informasi, Universitas Ma Chung, Villa Puncak Tidar Blok N-1 Malang, Indonesia \\ email:321410014@student.machung.ac.id ${ }^{1)}$
}

\begin{abstract}
Abstrak
Kurikulum dan rencana pembelajaran semester (RPS) merupakan bagian dalam perkuliahan yang berfungsi dalam mengatur seluruh kegiatan perkuliahan program studi dalam suatu periode tertentu. Penyusunan kurikulum memakan waktu yang lama dan harus memiliki panduan maupun standard yang baik. Salah satu program studi yang memiliki standard dalam perancangan kurikulum adalah program studi sistem informasi, yaitu Buku KKNI APTIKOM 2016. Perancangan kurikulum memiliki banyak proses seperti perumusan, evaluasi, validasi, hingga distribusi ke pihak terkait. Oleh karena itu, program studi sistem informasi memerlukan sebuah sistem yang dapat merancang kurikulum, mengevaluasi RPS serta mendistribusikan hasil kurikulum yaitu RPS kepada pihak terkait secara mudah dan cepat. Sistem yang digunakan menggunakan metode Three Major Phases dalam perkembangan serta menggunakan bahasa pemrograman PHP dan basis data MySQL
\end{abstract}

\section{Kata Kunci :}

Instrumen, kurikulum, rps, php, mysql.

\begin{abstract}
Curriculum and semester learning activity is a part of lecture activity which its function is to maintain the whole study program lectures activity in a period of time. Curriculum design process spends a lot of time and needs to have a good guidance or standard. One of study program which has a standard in design process of curriculum is information system study program, which is The Book of KKNI APTIKOM 2016. There's processes that need to be passed while designing a curriculum, such as data input, data evaluation, validation, until distribution to the involved stakeholder. Therefore, Information System Study Program needs a system which can design the curriculum, evaluate the semester learning activity, and also distribute the output to the stakeholders. System is built using Three Major Phases method, PHP as its programming language, and MySQL database to store its data.
\end{abstract}

\section{Keywords :}

Instrument, curriculum, semester learning activity, php, mysql.

\section{PENDAHULUAN}

Semakin berkembangnya teknologi pada berbagai bidang membuat pekerjaan ataupun proses menjadi cepat selesai. Diantara berbagai penggunaan teknologi pada banyak bidang, salah satu yang mendayagunakan teknologi adalah bidang pendidikan. Universitas adalah salah satu instansi yang bergerak pada bidang pendidikan dimana di dalamnya memiliki banyak kegiatan maupun proses. Universitas Ma Chung adalah salah satu contoh universitas yang mendayagunakan teknologi dalam kegiatannya. Beberapa penerapan teknologi di antaranya adalah penggunaan sistem MacIS, Ma Chung Learning Gateway, serta pendaftaran yang bersifat online melalui website universitas. Diantara banyaknya kegiatan dalam universitas, perancangan kurikulum merupakan kegiatan yang juga memerlukan sebuah sistem. Perancangan kurikulum memerlukan sistem dikarenakan kurikulum digunakan sebagai acuan dalam kegiatan perkuliahan, dimana di dalam proses perancangannya terdapat berbagai proses yang apabila dilakukan secara manual memakan waktu yang lama. 
Kurikulum ini dimiliki oleh setiap program studi Universitas Ma Chung. Salah satu program studi yang dapat dijadikan acuan dalam penyusunan kurikulum adalah program studi sistem informasi. Program studi sistem informasi digunakan sebagai acuan maupun studi kasus dikarenakan program studi ini memiliki panduan dalam penyusunan kurikulum yaitu Buku KKNI APTIKOM 2016 yang berisi standard-standard dalam pembuatan kurikulum dimana standard ini dapat diterapkan kedalam sebuah sistem informasi.

Terdapat juga masalah yang dalam perancangan kurikulum yang tidak hanya terdapat dalam program studi sistem informasi, di antaranya adalah proses distribusi RPS (output kurikulum yang berisi data silabus mata kuliah serta rancangan pertemuan perkuliahan) yang hanya dilakukan pada awal semester, proses pembagian materi yang tidak melalui satu pintu, serta banyaknya data yang akan diproses.

Tujuan dari dibangunnya sistem adalah untuk mempercepat proses perancangan kurikulum yang melibatkan banyak data, mendukung proses distribusi RPS dan materi, serta membangun sebuah sistem yang dapat merancang kurikulum berdasarkan satu standard pada program studi sistem informasi maupun pada seluruh program studi universitas.

Adapun batasan dari perancangan sistem ini adalah pada perumusan data umum (fakultas, prodi, dosen, dll), perumusan data kurikulum (profil lulusan, bidang kajian, dll), evaluasi data kurikulum, review mata kuliah, evaluasi RPS, dan distribusi materi perkuliahan. Metode yang digunakan dalam perancangan sistem adalah Three Major Phases yang terdiri dari proses analisis, desain, dan implementasi sistem. Sistem dibangun menggunakan bahasa pemrograman PHP dan menggunakan basis data MySQL.

\subsection{Tinjauan Pustaka}

Penelitian terdahulu dengan judul "Sistem Informasi Manajemen Tugas Akhir Berbasis Web" membahas sistem yang digunakan untuk manajemen proses pengajuan tugas akhir. Sistem ini diterapkan pada program studi Universitas Muhammadiyah Sidoarjo. Pada sistem ini, fitur yang terdapat hanya pengajuan online yang memudahkan mahasiswa agar tidak perlu ke kampus untuk pengajuan tugas akhir. Sistem ini dibuat dengan menggunakan bahasa pemrograman PHP dan database MySQL dengan metode pengembangan pengumpulan data, analisis, dan perancangan. Berbeda dengan penelitian terdahulu, sistem yang akan dikembangkan memiliki fitur yang tidak terdiri hanya dari pengajuan namun juga fitur evaluasi dan review. Sistem yang dikembangkan juga dapat digunakan oleh seluruh program studi universitas dan tidak terbatas pada satu program studi.

Penelitian lain yang diambil berjudul "Sistem Informasi Akademik Berbasis Web SMAN 1 Bandar". Sistem ini berfungsi sebagai pangkalan data sekolah (data guru, murid, rapor, kelas, pelajaran). Penelitian ini dikembangkan menggunakan metode menyerupai Three Major Phases, bahasa pemrograman PHP, dan database MySQL [1]. Berbeda dengan penelitian ini, sistem yang akan dikembangkan tidak hanya berfungsi sebagai pangkalan data namun juga berfungsi sebagai perumus kurikulum dan RPS yang mendetailkan setiap pertemuan saat kegiatan perkuliahan dilaksanakan [2]. Sistem tidak hanya berisi data umum namun juga data yang berbeda dari setiap program studi.

Three Major Phases adalah sebuah metode turunan SDLC yang terdiri dari 3 (tiga) tahapan utama yang terdapat pada setiap tahap SDLC. Tujuan dari metode ini adalah untuk untuk menganalisis permasalahan dilanjutkan dengan mendesain sistem sebagai solusi, kemudian melakukan implementasi pada desain sistem tersebut dimana metode tidak sepanjang SDLC sehingga sistem dapat selesai dengan cepat.

Kurikulum adalah seperangkat rencana dan sebuah pengaturan berkaitan dengan isi, tujuan, bahan ajar, dan cara yang digunakan sebagai pedoman dalam penyelenggaraan tujuan 
URL : https://jurnal.machung.ac.id/index.php/kurawal

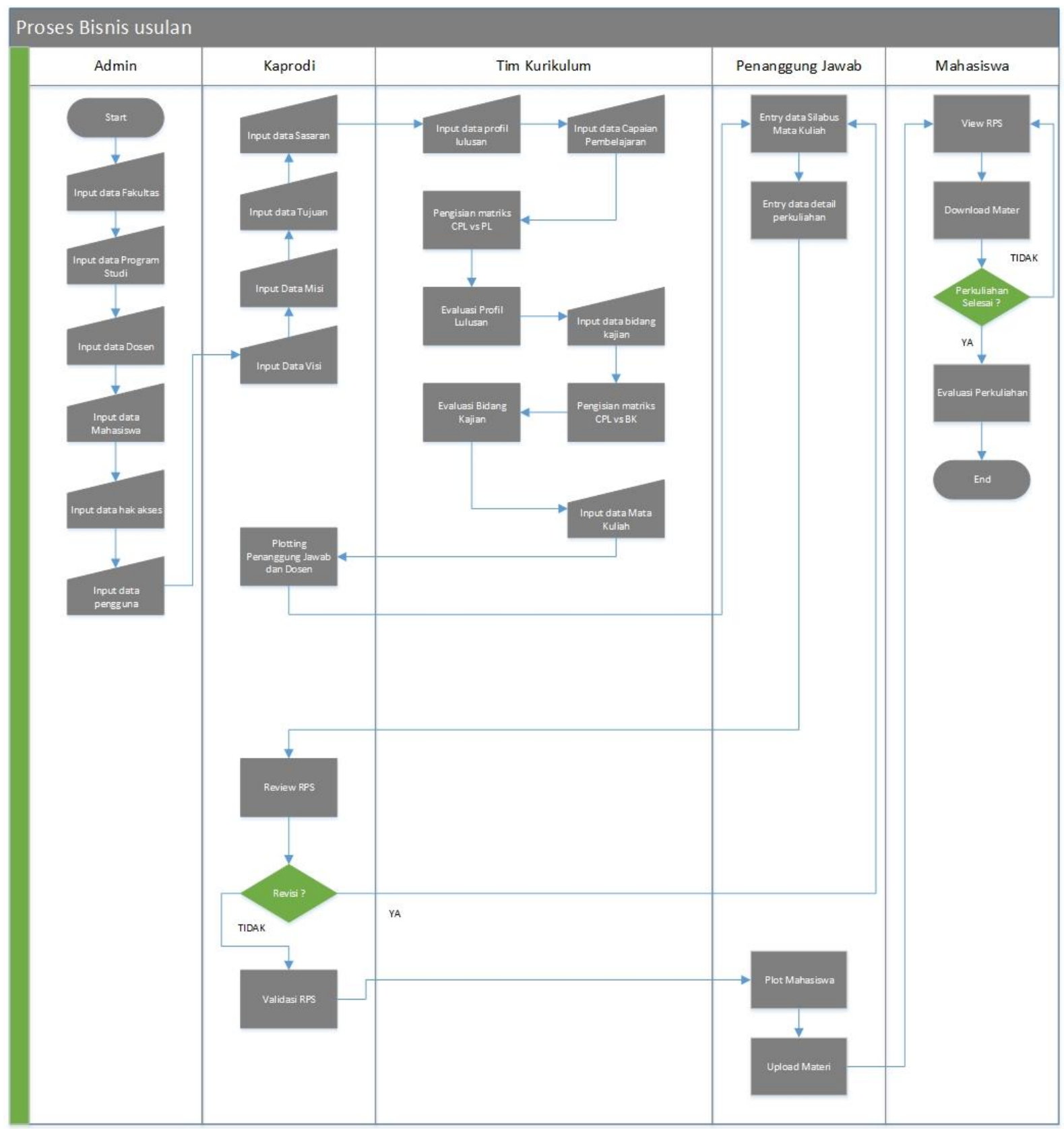

Gambar 1 Proses Bisnis Sistem

pendidikan nasional. Alur dari penyusunan kurikulum menurut Buku KKNI APTIKOM 2016 terdiri dari:

1) Identifikasi awal.

2) Perumusan profil lulusan.

3) Perumusan capaian pembelajaran.

4) Perumusan bidang kajian.

5) Pengisian/penetapan mata kuliah.

6) Penyusunan silabus mata kuliah.

7) Penyusunan RPS mata kuliah

8) Siklus pelaporan (reporting) [3].

Pada sistem yang dibangun RPS bersifat sebagai output yang berisi kegiatan detail perkuliahan beserta materi. 


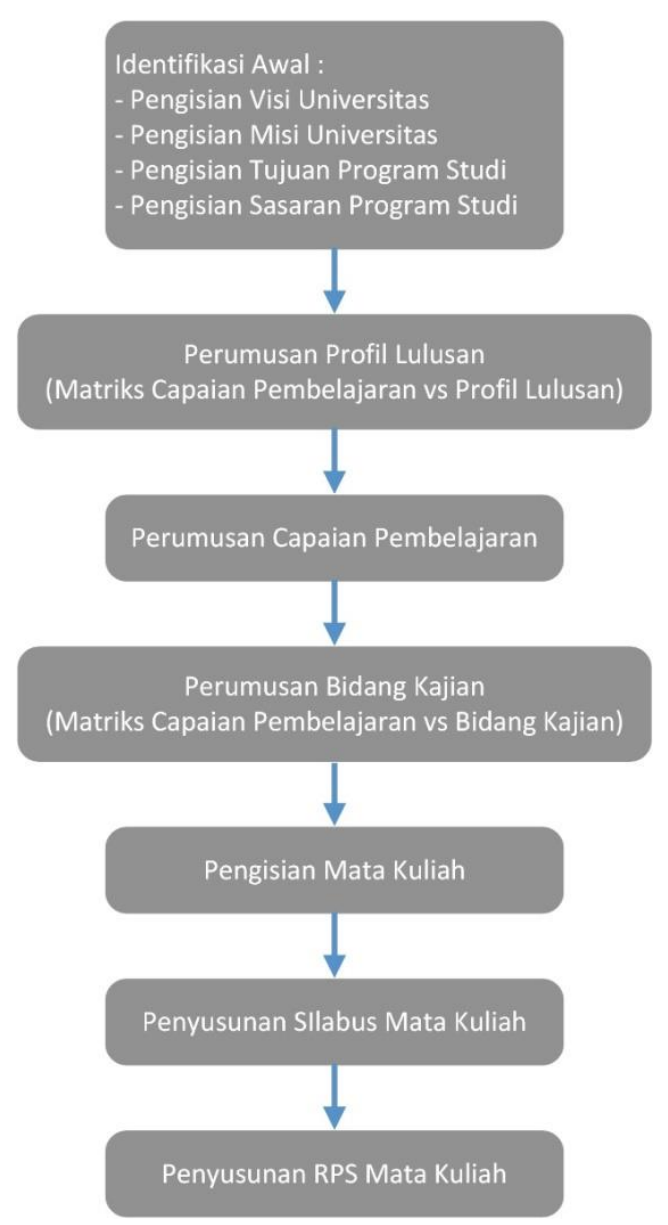

Gambar 2 proses penyusunan kurikulum

Rencana pembelajaran semester atau RPS adalah penyusunan rencana pelaksanaan pembelajaran untuk setiap muatan pembelajaran.

UML atau Unified Modelling Language adalah penggambaran batasan-batasan dari sebuah sistem, menggambarkan kegiatan atau suatu proses yang terdapat pada sebuah sistem, hingga menggambarkan gambaran dari database yang digunakan sistem [4].

Use Case Diagram adalah bagian dari UML yang digunakan untuk mendeskripsikan sebuah interaksi antara satu atau lebih aktor dengan sistem informasi yang akan dibuat [5].

Activity Diagram adalah diagram yang menggambarkan suatu workflow atau aktivitas, proses, ataupun menu yang terdapat pada sistem [6].

Entity Relationship Diagram adalah sebuah UML yang digunakan dalam pemodelan awal basis data yang akan dikembangkan berdasarkan teori himpunan dalam bidang matematika untuk pemodelan basis data relasional [7].

MySQL database adalah salah satu aplikasi yang menangani pengaturan database, dengan menggunakan MySQL data dapat diakses dengan cepat [8].

\section{METODE / ALGORITMA}

Metode yang digunakan dalam pengembangan sistem adalah metode Three Major Phases. Dua dari tiga tahap Three Major Phases akan dibahas yaitu bagian analisis dan bagian desain. Metode analisis terdiri dari data gathering yang berarti pengumpulan data dan data flow and decision analysis yang berarti analisis terhadap keputusan-keputusan yang akan diterapkan 
pada sistem berdasarkan masalah yang ditemukan pada tahap analisis pertama. Pada setiap tahap terdapat pemecahan kegiatan yang dilakukan. Proses data gathering memiliki kegiatan study of literature yaitu analisis permasalahan dan kebutuhan sistem melalui dokumendokumen yang disediakan oleh stakeholder sistem.

Proses kedua dari analisis yaitu data flow and decision analysis memiliki 4 (empat) kegiatan yang di antaranya adalah:

1) Problem solving analysis, identifikasi masalah yang terdapat pada studi kasus dan mencari solusi secara sistem.

2) Business process analysis, analisa proses bisnis berjalan, mencari kekurangan, dan membuat usulan proses bisnis baru melalui sistem.

3) Human requirement analysis, analisa kebutuhan sumber daya manusia pada sistem dan pengaturan hak akses setiap sumber daya manusia.

4) System requirement analysis, Analisa kebutuhan fungsional dan non-fungsional sistem.

Selanjutnya adalah proses desain yang memiliki tiga tahap yaitu data entry design, I/O design, serta data organization. Pembagian kegiatan juga dilakukan per masing-masing tahap proses desain. Tahap data entry design memiliki kegiatan di antaranya:

1) User access design, lanjutan human requirement analysis yang menjelaskan hak akses setiap pengguna menggunakan use case diagram.

2) System activity design, bagian yang membahas alur dalam sistem menggunakan activity diagram.

Sedangkan untuk $I / O$ design terdiri dari mockup design yang menggambarkan rancangan sistem berbentuk mockup dan data organization terdiri dari relational database design yang menjelaskan susunan database.

Berdasarkan data gathering yang dilakukan, sistem dibangun menurut penyusunan kurikulum APTIKOM 2016 dan memiliki penyesuaian dalam output dan data berdasarkan dokumen Panduan Penyusunan Kurikulum Program Studi di Universitas Ma Chung.

Setelah dilakukan analisis pada dokumen ditemukan beberapa permasalahan pada penyusunan kurikulum program studi sistem informasi yang di antaranya:

1) Proses penyusunan yang memiliki data-data yang saling memiliki ketergantungan.

2) Diperlukannya matriks yang digunakan untuk keperluan evaluasi.

3) RPS harus memiliki validasi dan control.

4) Mahasiswa hanya dapat melihat silabus maupun RPS hanya pada awal perkuliahan.

5) Pembagian materi setiap pertemuan yang tidak melalui satu pintu.

Solusi untuk masalah pertama adalah penyusunan data master yang dilakukan secara berurutan agar integrasi pada setiap data dapat terjaga. Proses dilakukan secara bertahap dari pengisian data umum hingga data kurikulum.

Berdasarkan desain aktivitas mastering pada sistem menggunakan contoh mastering profil lulusan (Gambar 3), terdapat proses yang memeriksa apakah data yang dibutuhkan pada aktivitas tersebut sudah tersedia atau tidak. Apabila data belum tersedia maka sistem akan mengarahkan pengguna ke data yang harus diisi terlebih dahulu. Beberapa integrasi data yang terdapat dalam sistem adalah:

1) Data misi membutuhkan data visi.

2) Data profil lulusan membutuhkan data misi.

3) Data capaian pembelajaran membutuhkan data profil lulusan.

4) Data bidang kajian membutuhkan data capaian pembelajaran.

5) Seluruh data dipanggil kembali pada proses mastering mata kuliah. 
URL : https://jurnal.machung.ac.id/index.php/kurawal

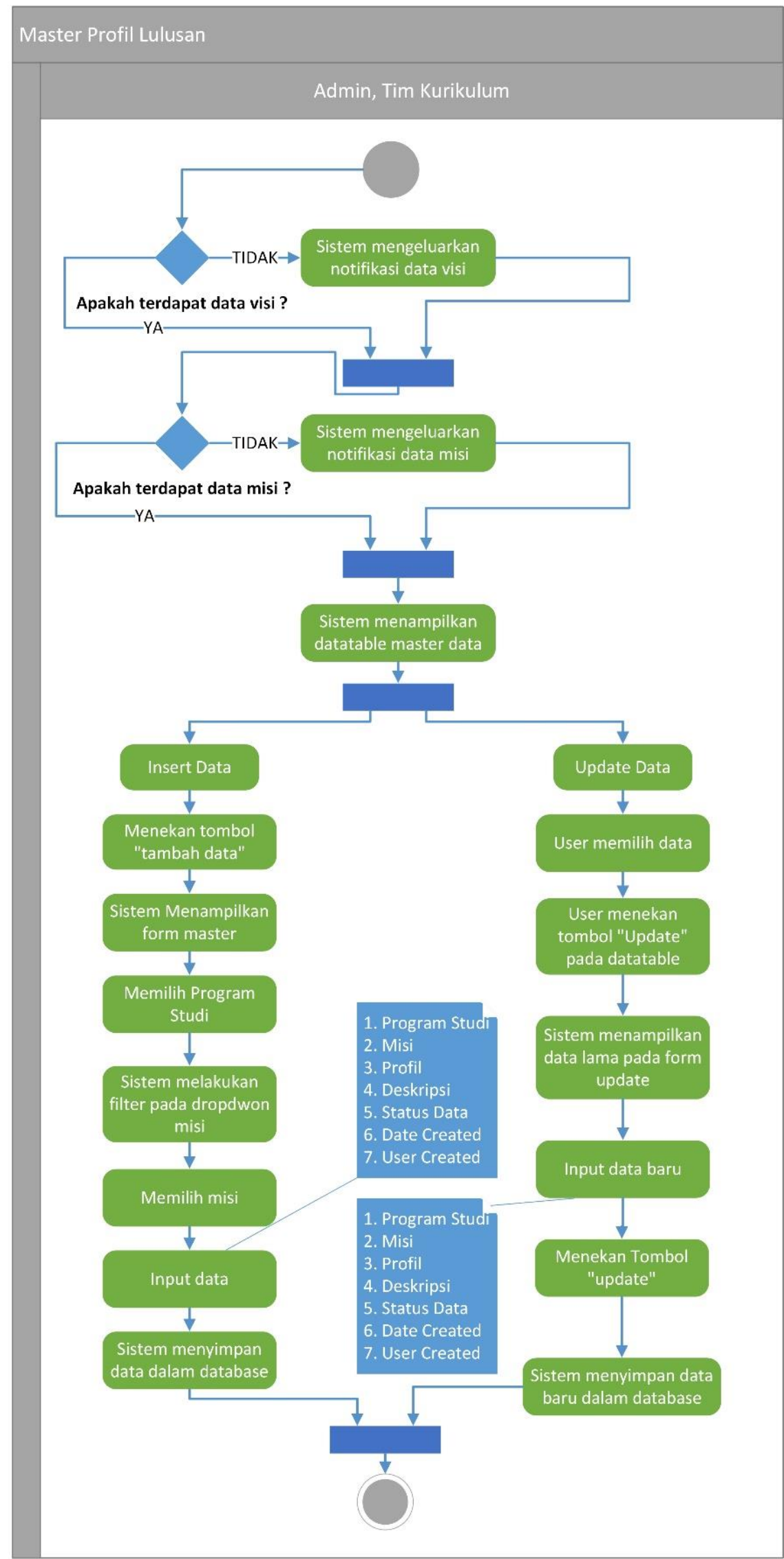

Gambar 3 activity diagram mastering profil lulusan 
Aktivitas mastering lainnya memiliki perancangan yang sama dengan mastering profil lulusan. Setelah seluruh data telah dimasukkan maka dilanjutkan dengan proses evaluasi data kurikulum (profil lulusan \& bidang kajian) menggunakan matriks yang membandingkan data kurikulum dengan data capaian pembelajaran.

Rancangan dari matriks CPL vs PL (Gambar 4) memperlihatkan bahwa pengguna hanya perlu untuk mengisi apakah data kurikulum yang dibandingkan dengan data capaian pembelajaran. Setelah selesai maka pengguna dapat kembali ke bagian mastering untuk mengaktifkan data kurikulum yang memenuhi syarat berdasarkan penghitungan pada matriks. Bagian transaksi matriks ini menjawab permasalahan kedua pada studi kasus.

Setelah data kurikulum selesai dievaluasi dan data mata kuliah ditetapkan, proses berikutnya adalah plotting dosen pembimbing, penyusunan silabus (data mata kuliah), penyusunan RPS, dan validasi mata kuliah. Proses plotting dosen dilakukan oleh kaprodi dimana proses ini bertujuan untuk menentukan setiap penanggung jawab mata kuliah pada saat penyusunan silabus dan RPS. Data silabus mata kuliah tidak akan dapat diisi apabila dosen penanggung jawab belum ditentukan oleh kaprodi.

Data dari RPS dapat diisi saat data silabus selesai diisi oleh penanggung jawab mata kuliah. Setelah pengisian data silabus mata kuliah dan RPS selesai dilakukan, penanggung jawab mata kuliah dapat melakukan upload materi perkuliahan per pertemuan pada detail RPS yang telah dirancang terlebih dahulu sebelumnya. Setelah dosen penanggung jawab selesai melakukan input data, maka penanggung jawab dapat mengubah status mata kuliah menjadi "selesai". Data mata kuliah ini selanjutnya diteruskan ke kaprodi untuk proses validasi.

Setelah mata kuliah divalidasi, maka mahasiswa dapat secara langsung melihat RPS dari setiap mata kuliah pada hak akses mahasiswa sistem (Gambar 5). Hal ini menjawab permasalahan ketiga dimana mahasiswa sekarang tidak hanya dapat melihat RPS pada awal perkuliahan namun dapat diakses kapanpun. Selain melihat RPS mahasiswa dapat juga melakukan evaluasi RPS setiap pertemuan selesai melalui sistem dan evaluasi mata kuliah saat semester berakhir. Evaluasi ini bertujuan sebagai control dari RPS agar selalu diperbarui dan terjaga kualitasnya berdasarkan evaluasi dari mahasiswa.

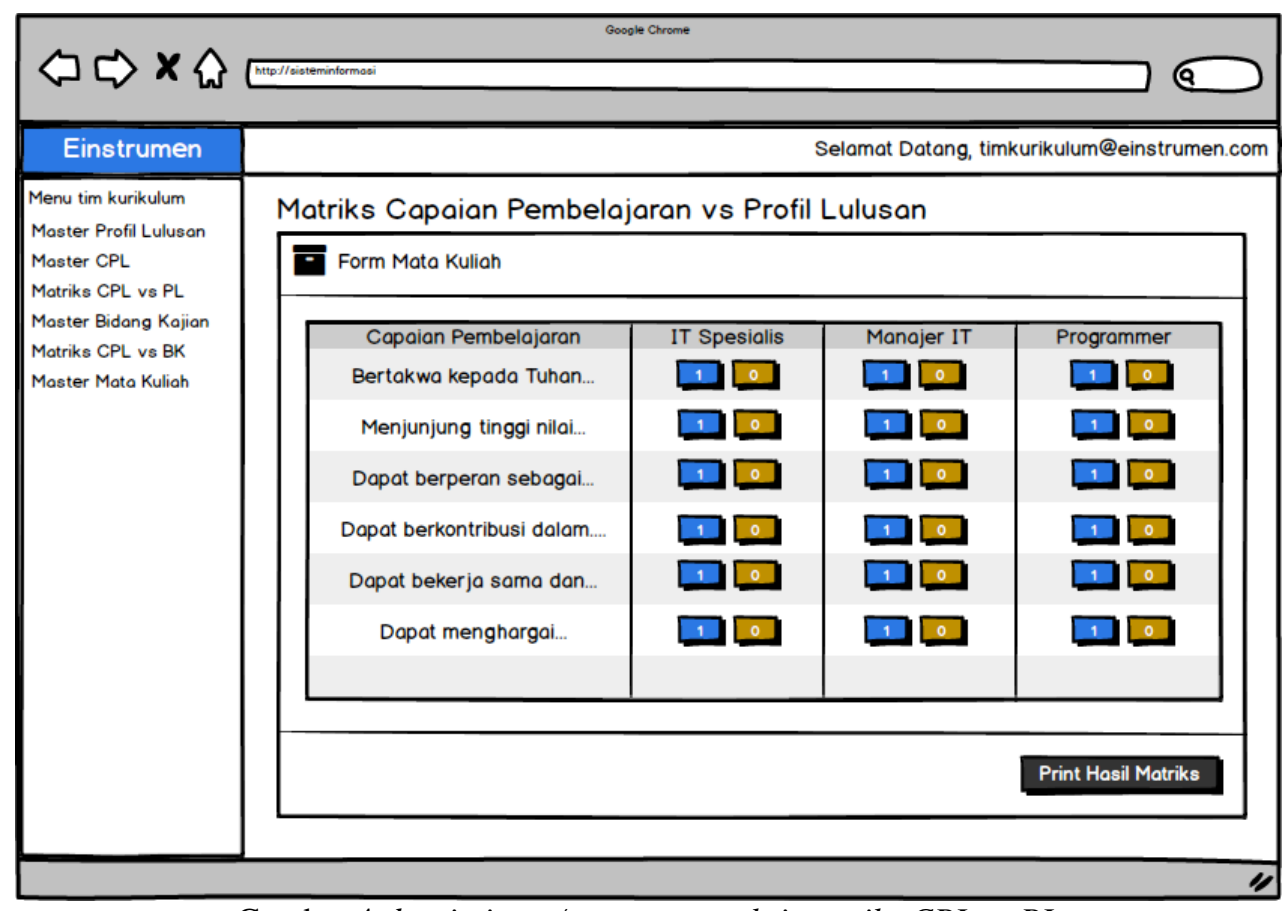

Gambar 4 desain input/output transaksi matriks CPL vs PL 
URL : https://jurnal.machung.ac.id/index.php/kurawal

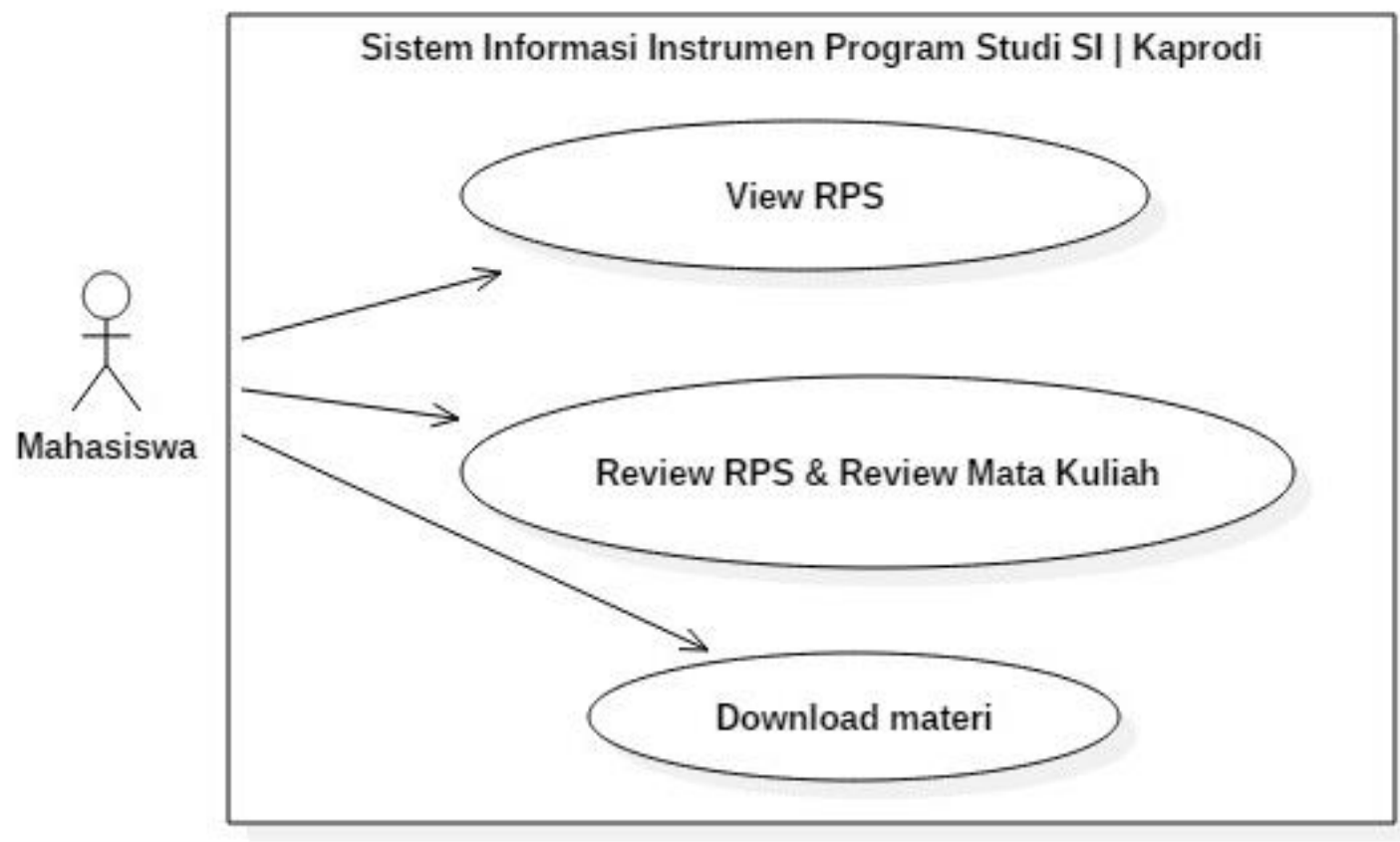

Gambar 5 hak akses proses penetapan mata kuliah

Proses kontrol dari RPS dan data kurikulum ini akan dilakukan secara bertahap dimana RPS setiap tahun akan diperbarui dan data kurikulum setiap 4 (empat) tahun sekali. Sedangkan untuk penyebaran atau distribusi materi sistem menggunakan proses upload materi per-RPS saat RPS selesai dibuat dan mahasiswa dapat melakukan akses download pada materi tersebut.

Output atau hasil yang terdapat pada sistem ini antara lain adalah RPS yang berisi data mata kuliah dan rancangan kegiatan pertemuan mata kuliah selama satu semester, laporan hasil penghitungan matriks, laporan hasil review RPS per pertemuan, laporan hasil evaluasi mata kuliah, dan laporan kurikulum.

\section{HASIL DAN PEMBAHASAN}

Berdasarkan hasil analisis dan solusi yang terdapat pada bagian perancangan maka pembangunan sistem informasi instrument kurikulum dan evaluasi RPS memiliki 5 (lima) macam hak akses yaitu:

1) Admin, akses pada data kurikulum dan data umum.

2) Tim kurikulum, akses pada data kurikulum dan penggunaan matriks.

3) Kaprodi, akses pada review mata kuliah.

4) Penanggung jawab mata kuliah, akses pada penyusunan silabus dan RPS.

5) Mahasiswa, akses pada view RPS dan evaluasi mata kuliah. Mahasiswa juga dapat melakukan evaluasi RPS perkuliahan dan evaluasi mata kuliah pada sistem (Gambar 6).

Sedangkan sistem informasi memiliki beberapa fitur yang mendukung perancangan RPS. Beberapa fitur ini di antaranya adalah:

1) mastering data umum.

2) mastering data kurikulum.

3) Evaluasi data kurikulum.

4) Penyusunan silabus mata kuliah.

5) Penyusunan RPS mata kuliah.

6) Distribusi materi mata kuliah. 
7) Evaluasi RPS dan mata kuliah.

Ketujuh fitur ini dapat membantu agar kurikulum dapat lebih mudah dirancang, akses terhadap data RPS mudah, kualitas RPS dan mata kuliah terjaga, dan penyebaran materi menjadi lebih baik.

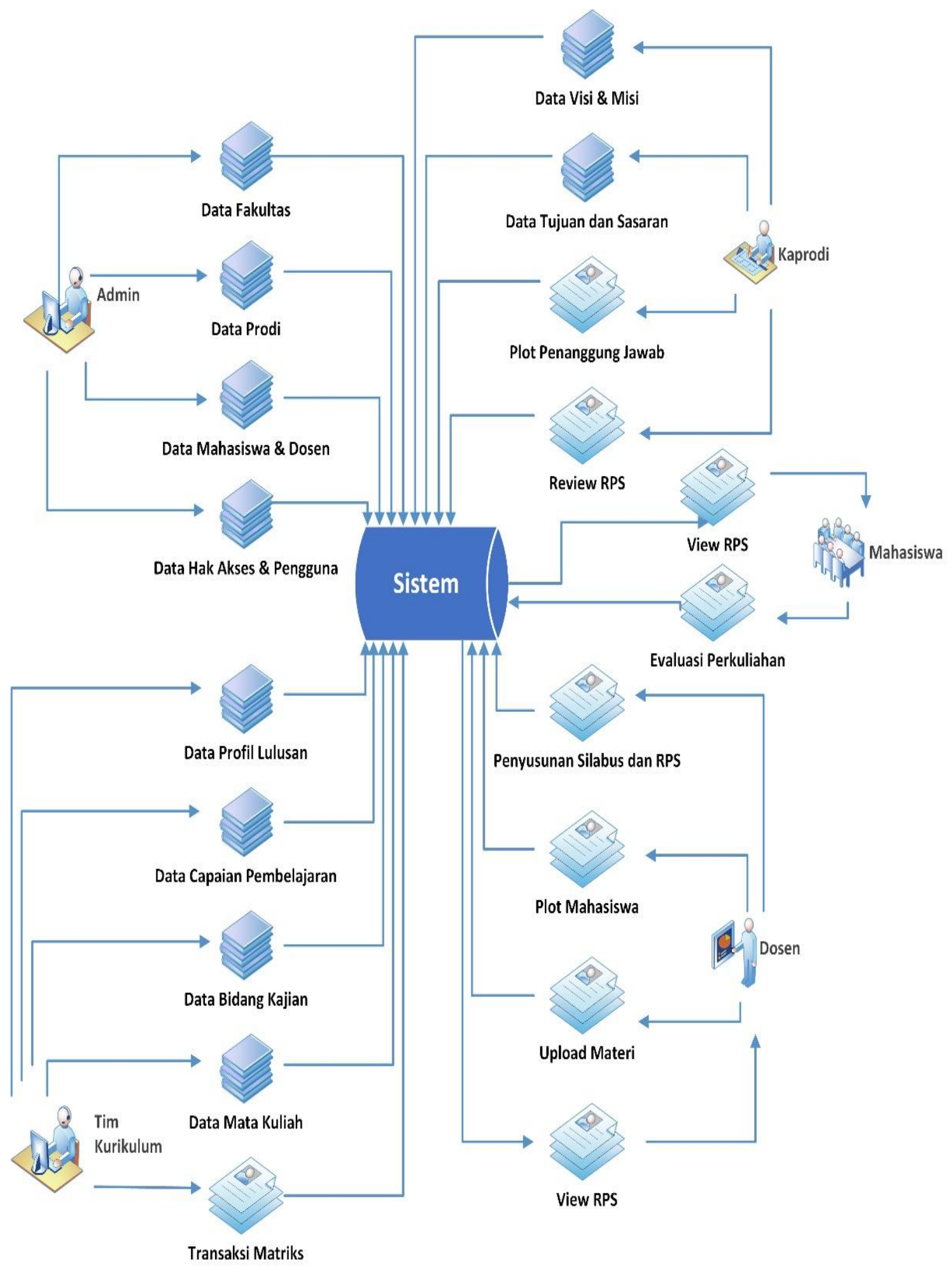

Gambar 6 sitemap sistem 


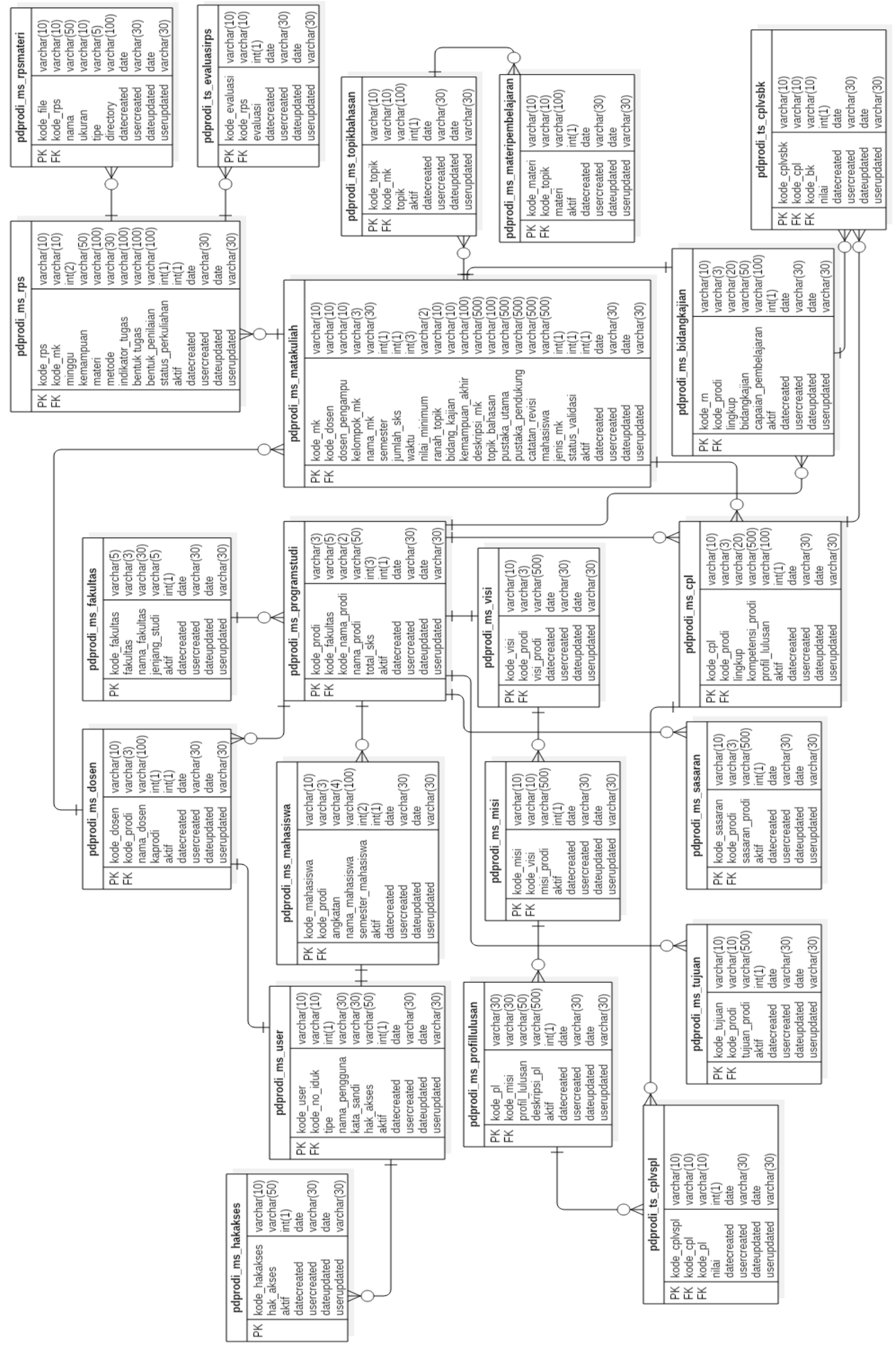

Gambar 7 Entity Relationship Diagram Database 


\section{KESIMPULAN}

Sistem instrumen dan evaluasi RPS dikembangkan menggunakan panduan penyusunan kurikulum dari Buku KKNI APTIKOM 2016 yang disesuaikan dengan kebutuhan universitas. Pada pengembangannya sistem dikembangkan menggunakan metode three major phases, bahasa pemrograman PHP, dan database MySQL. Sistem ini dapat juga diterapkan pada program studi lain yang ada pada universitas, tidak hanya pada program studi sistem informasi saja.

Sistem informasi instrument dan evaluasi juga membuat program studi tidak mengerjakan perancangan secara manual, pencarian data yang lebih cepat, dan proses distribusi data kurikulum yang lebih baik.

Adapun saran bagi pengembangan sistem adalah sebagai berikut:

1) Sistem dapat dikolaborasikan dengan sistem penjaminan mutu untuk lebih menjamin kualitas dari RPS maupun mata kuliah berdasarkan review dari mahasiswa.

2) Sistem dapat diterapkan pada seluruh program studi selain sistem informasi pada universitas.

\section{REFERENSI}

[1] Fuah, A. M., Winarno, 2014, Peternakan Terpadu: Konsep Rancang dan Aplikasi, PT. Penerbit IPB Press, Bogor.

[2] Kunjaya, Chatief. dkk., 2018, Panduan Penyusunan Kurikulum Program Studi Universitas Ma Chung. Universitas Ma Chung, Malang.

[3] Tim KKNI APTIKOM, 2016, Naskah Akademik Kerangka Kualifikasi Nasional Indonesia Bidang Ilmu Informatika dan Komputer, Depok.

[4] Sugiarti, Yuni, 2013, Analisis dan Perancangan UML, generated VB 6, Jakarta.

[5] Sukamto, Rosa Ariani \& Shalahuddin, Muhammad, 2013, Rekayasa Perangkat Lunak, Informatika, Bandung.

[6] Nugroho, Ibrahim, 2011, Consistency Rules Between UML Use Case and Activity Diagrams Using Logical Approach, Jakarta.

[7] Ladjamudin, Al-Bahra Bin, 2013, Analisis dan Desain Sistem Informasi, Graha Ilmu, Jakarta.

[8] Kadir, Abdul, 2013, Pengertian MySQL, mediakom, Yogyakarta. 